

\section{A geografia escolar e o papel da geografia física}

\section{La geografía escolar y el papel de la geografía física School Geography and the Role of Physical Geography}

Jully Gabriela Retzlaf de Oliveira*

\section{Resumo}

A geografia escolar no ensino fundamental e médio tem por objetivo contribuir para a construção da cidadania, buscando alfabetizar o aluno na leitura do espaço geográfico em suas diversas escalas e configurações. Atualmente tem-se observado certa precarização do ensino de conteúdos físico-naturais na disciplina de Geografia, sobressaindo a memorização e a descrição dos fenômenos físicos. Diante desse contexto, este trabalho teve por objetivo refletir sobre a geografia escolar e o papel da geografia física na formação do aluno. Para tanto, como metodologia procedeu-se a leitura e a revisão de referencial teórico ligado ao tema pesquisado. Em síntese, pode-se afirmar que a geografia física volta-se para o conhecimento aprofundado da composição e dinâmica processual da natureza, bem como as derivações oriundas de sua apropriação e transformação pela sociedade; portanto, deverá permitir uma visão holística da realidade, olhando para os fatores, características e processos que influenciam o meio ambiente e como esses elementos interagem, assegurando uma correta análise do espaço, mantendo o princípio de uma geografia global.

\section{Palavras-chave}

Geografia escolar; cidadania; questão ambiental

* Prof. ${ }^{a}$ Universidade Estadual do Norte do Paraná, UENP, Cornélio Procópio, PR. 


\section{Palabras clave $\mid$ Resumen}

Geografía escolar; ciudadanía; problemas ambientales
La geografía escolar en la educación primaria y secundaria tiene el objetivo de contribuir a la construcción de la ciudadanía, buscando la alfabetización de los estudiantes en pro de una lectura espacial de diversas escalas y configuraciones. Actualmente hemos evidenciado cierta precariedad en los contenidos de enseñanza físico-naturales en la disciplina geográfica, destacando la memorización y la descripción de los fenómenos físicos. Teniendo en cuenta este contexto, el presente estudio tiene como objetivo reflexionar sobre la geografía escolar y el papel de la geografía física en la formación del estudiante. Metodológicamente se procedió a la lectura y revisión teórica sobre el tema buscado, por lo que se puede afirmar que la geografía física se vincula con el profundo conocimiento de la composición y procedimiento dinámico de la naturaleza y, asimismo, con las derivaciones que surgen de su apropiación y transformación por parte de la sociedad. Por lo tanto, esta debe permitir una visión integral de la realidad, reconociendo factores, características y procesos que influyen en el medioambiente para vislumbrar cómo interactúan entre sí, asegurando un correcto análisis del espacio y manteniendo el principio de una geografía mundial.

\section{Keywords}

School geography; citizenship; environmental issues

\section{Abstract}

The school geography in primary and secondary education is to contribute to the construction of citizenship, seeking literacy students in reading the geographic space in its various scales and settings. Currently we have seen certain precariousness of teaching physical-natural contents in Geography discipline, highlighting the memorization and the description of physical phenomena. In this context, this study aimed to reflect on the school geography and the role of physical geography in the formation of the student. Therefore, as a methodology proceeded to reading and theoretical review on the topic searched. In summary, it can be said that the physical geography back to the in-depth knowledge of the composition and procedural dynamics of nature and the derivations arising from its appropriation and transformation of society, therefore, must allow a holistic view of reality, looking for the factors, features and processes that influence the environment and how these elements interact, ensuring a correct analysis of space, maintaining the principle of a global geography. 


\section{Introdução}

Ensinar Geografia significa possibilitar ao aluno raciocinar geograficamente o espaço terrestre em diferentes escalas, em uma dimensão cultural, econômica, ambiental e social (Castellar \& Vilhena, 2010). O espaço geográfico tem como gênese de sua diferenciação tanto as construções próprias da Natureza quanto a produção da Sociedade humana. Desta condição deriva a concepção de que a Geografia é uma ciência voltada ao estudo da produção do espaço a partir da interação Sociedade-Natureza. Nesta perspectiva, a Geografia física volta-se para o conhecimento aprofundado da composição e dinâmica processual da natureza, bem como as derivações oriundas de sua apropriação e transformação pela sociedade (Mendonça, 2009).

Atualmente tem-se questionado o tratamento didático dado aos temas físicos da Geografia, tanto no que se refere ao material didático quanto às práticas de ensino adotadas em sala de aula. Com efeito, tem-se observado, a partir de relatos e acompanhamentos do estágio supervisionado, certa precarização do ensino de Geografia física na escola, sobressaindo a memorização e a descrição dos fenômenos físicos, características herdadas do tempo de surgimento deste ramo da Geografia. Como resultado as aulas tornam-se tediosas, enfadonhas e sem significado para o aluno.

Diante desse contexto, este trabalho tem por objetivo refletir sobre a Geografia Escolar e o papel da Geografia Física na formação do aluno. Ainda que seja a partir do universo teórico, torna-se interessante à medida que nos aponta caminhos e direcionamento teóricos metodológicos para abordar os conteúdos físicos nas aulas de Geografia da educação básica. Para tanto, como metodologia procedeu-se a leitura e revisão de referencial teórico ligado ao tema pesquisado.

\section{A Geografia Escolar: alguns apontamentos}

A Geografia é uma das lentes que permite a leitura do planeta Terra, a morada do homem, o lugar das múltiplas relações. Dessa forma, torna-se necessária uma maior compreensão do espaço geográfico (Kozel, 1998). No início, com a necessidade de desvendar o ambiente terrestre, o saber geográfico esteve ligado aos governantes, guerreiros, negociantes e viajantes. Nessa perspectiva, inúmeros trabalhos de cunho geográfico surgiram da observação e descrição dos lugares (Kozel, 1998).

A Geografia como ciência surge na Alemanha para responder duas necessidades básicas: a unificação do território e a conquista de um lugar privilegiado para a Alemanha no conjunto das demais nações europeias. E essas necessidades só poderiam ser resolvidas através da criação do Estado nacional e da expansão territorial (Pereira, 2009). Esta disciplina contribuiu para o expansionismo europeu e para a estruturação do capitalismo no mundo, pautada na descrição dos vários lugares das colônias e suas riquezas (Moura \& Alves, 2002). Na Alemanha, o papel da Geografia é de viabilizar unidade do território; já na Inglaterra e França é de viabilizar a expansão colonial (Pereira, 2009).

Na Alemanha, a Geografia esteve presente, primeiramente, no currículo Escolar desde a escola primária até os cursos universitários (Moura \& Alves, 2002). Esse país foi o pioneiro em introduzir essa disciplina no currículo escolar, sendo ensinada pela primeira vez por Kant na Universidade de Konigsberg em 1756, que a concebia como "síntese dos conhecimentos sobre natureza", tendo como objetivo descrever os fenômenos manifestados na superfície terrestre (Kozel, 1998). A Geografia era um conhecimento útil, capaz de facilitar um projeto político que leva à unificação territorial (Pereira, 2009). Segundo a autora, o objetivo da Geografia Escolar residia na inculcação de uma ideologia nacionalista e patriótica veiculada através da ideia de que a forma estado-nação ou país é natural e eterna. Nesse contexto "a Geografia é incluída nos currículos por razões geopolíticas enquanto não só marca a naturalidade do homem no espaço, mas também sustenta que o homem só é humano porque está incluído num espaço politizado, nacional" (p.27). O ensino de Geografia, ao ser introduzido nas escolas, surge comprometido não apenas com o Estado nacional, mas também com o capitalismo, que se consolida no território alemão (Kozel, 1998).

Na França, em 1870 no pós-guerra franco-prussiana, a Geografia passou a ter mais presença no primário, no secundário e na universidade (Moura \& Alves, 2002). Com o apoio do Estado, a Geografia é instituída como disciplina em todas as séries do ensino básico e são criadas as cátedras e institutos de Geografia, tornando-se necessário para pensar e refletir do espaço. Novamente a teoria geográfica vai de encontro às iniciativas dos estados, que necessitavam conhecer melhor seus domínios, servindo de suporte para evolução capitalista (Kozel, 1998).

A Geografia tradicional elimina o raciocínio e a compreensão e leva à listagem de conteúdos, disposta em uma ordem enciclopédica, priorizando os elementos da natureza, tornando o ensino de Geografia acrítico e a-histórico, não considerando que todo arranjo espacial contém em si relações sociais (Pereira, 2009). Para a autora, ocorre nesse período uma minimização das relações sociais, dificultando o entendimento da construção do espaço geográfico como fruto de contradições ao longo do processo histórico, consagrando o modo dualista de encarar o homem e a natureza. A Geografia deste período considera o aluno como um ser neutro, sem vida, sem cultura, sem história, sem espaço. $O$ aluno não pode ver-se no espaço geográfico que estuda e é desprezado como ser histórico (Pereira, 2009)

A Geografia como disciplina escolar no século xIX contribuiu para o expansionismo europeu; descrição dos vários lugares das colônias e suas riquezas; conhecimento do próprio território europeu e veiculação 
através da própria disciplina princípios, valores, ideias de patriotismo. Dessa forma, teve objetivo de contribuir para a formação dos cidadãos a partir da difusão da ideologia nacionalista, em franca sintonia com os interesses políticos econômicos dos vários Estados-nações - patriotismo, descrição do quadro natural (Moura \& Alves, 2002).

O peso da descrição física na Geografia Escolar foi sempre importante. O objetivo não é o de raciocinar sobre o espaço, mas de fazer dele um inventário, para delimitar o espaço nacional e situar o cidadão neste quadro. Desse modo o discurso nacionalista reforçou o peso dos elementos físicos (Brabant, 2003).

Nesse momento imperavam a dicotomia entre a Geografia Física e Humana, a mera listagem de conteúdos dispostos em uma ordem enciclopédica, a memorização de dados e a descrição de paisagens (Moura \& Alves, 2002). 0 enciclopedismo contribuiu para a abstração crescente do discurso geográfico, ao mesmo tempo em que alimentou o tédio das gerações de alunos que classificaram a Geografia entre as matérias a memorizar (Brabant, 2003).

A Geografia somente passa ser sistematizada em meados do século XIX, com as obras de Alexandre Humboldt (Quadros da Natureza e Cosmos) e Karl Ritter (Geografia Comparada) (Kozel, 1998). Humboldt considerava a Geografia como síntese de todos os conhecimentos relativos à natureza e à superfície terrestre e Ritter procurava estabelecer relações entre os diferentes lugares colocando o homem como elemento principal (Kozel, 1998).

Ainda na Alemanha (1882), Ratzel publica a AntropoGeografia, enfatizando a influência que a natureza exerce sobre os homens, interferindo em suas condições econômicas e elabora o conceito de Espaço Vital, que estabelece as bases da geopolítica. Já a escola francesa liderada por Paul Vidal de La Blache defendia que o homem seria um ser ativo que sofre influência do meio, entretanto, atua sobre ele e o transforma e, então a natureza passa a ser encarada como meio possível para a ação humana (Kozel, 1998).

Alfred Hettner, geógrafo alemão, propõe outra vertente geográfica: o estudo da diferenciação das áreas. Porém este enfoque somente passou a ser discutido quando o geógrafo americano Richard Hartshorne o desenvolve e o aprimora na década de 30 . Hartshorne, em 1959, publica a obra "Questões sobre a Natureza da Geografia", mantendo a essência das antigas abordagens geográficas. A variação das áreas passa a ser o cerne da Geografia, assim como seu instrumento de análise (Kozel, 1998).

Na década de 50, a Geografia passa a ser questionada quanto ao seu objeto e métodos de interpretação, pois o estudo das regiões e fenômenos visíveis, parcelizados e descritivos da paisagem já não conseguiam explicar as transformações ocorridas (Kozel, 1998). Nas décadas de 60 e 70, a Geografia não conseguia apreender a complexidade pela qual o mundo vivia, surgindo nos EUA movimentos de renovação, caracterizados pela diversidade de concepções. Todavia, podem-se destacar duas correntes do pensamento: a Geografia Pragmática e a Geografia Crítica (Kozel, 1998).
A Geografia Pragmática busca a renovação das técnicas de pesquisa procurando linguagens mais condizentes com a nova realidade imposta pelo planejamento. Consiste em uma mudança de forma, desconsiderando o social e apropriando-se de técnicas oriundas da matemática na intenção de explorar o espaço geográfico (Kozel, 1998). Nesse sentindo a Geografia mais uma vez está a serviço do poder colaborando na reorganização dos territórios.

Em paralelo à Geografia Pragmática surge a Geografia da Percepção, contestando o excesso de quantificação, onde o homem era apenas um número, focalizando no entendimento de como o homem percebe o ambiente onde vive, explicando a valorização subjetiva do espaço (Kozel, 1998).

A Geografia Crítica propõe um rompimento radical tanto com a Geografia tradicional quanto com a Pragmática, propondo um discurso geográfico político que ao analisar o espaço o concebe como produto da sociedade em sua relação com o trabalho e o capital (Kozel, 1998). Esse movimento crítico tem como elemento unificador a utilização do materialismo histórico e dialético como corpo teórico e metodológico de investigação da realidade (Oliveira, 2003). A Geografia Crítica concebe o espaço como espaço social construído pleno de lutas e conflitos sociais, colocando-se como ciência social, mas também estuda a natureza enquanto recurso apropriado pelos homens e quanto uma dimensão da história, da política (Vesentini, 2003).

No ensino, a Geografia Crítica preocupa-se com o senso crítico do educando e não em arrolar fatos para que ele os memorize. $O$ conhecimento não se localiza no professor ou na ciência a ser ensinada e sim, no real, no meio onde o aluno e professor estão situados, e é fruto da práxis coletiva dos grupos sociais. Integrar o educando no meio significa deixá-lo descobrir que pode torna-se sujeito na história (Vesentini, 2003).

No momento atual vive-se um embate teórico-metodológico e prático realizado em três frentes: entre a New Geography e a Geografia Tradicional de um lado, entre a Geografia Crítica e a Geografia Tradicional de outro e, ainda, entre a New Geography e a Geografia Crítica. Na prática não há condições de afirmar que a hegemonia é desta ou daquela corrente (Oliveira, 2003).

As propostas de reformulação do ensino de Geografia apontam para as possibilidades da Geografia e da prática de ensino cumprirem papéis politicamente voltados aos interesses das classes populares, tendo que considerar o saber e a realidade do aluno como referência para o estudo do espaço geográfico. Dessa forma, o ensino de Geografia não se deve pautar pela descrição e enumeração de dados, ao contrário, esse deve propiciar ao aluno a compreensão do espaço geográfico em sua concretude, nas suas contradições (Cavalcanti, 1998).

A esse respeito, Moura e Alves (2002) colocam que a Geografia do século $x x I$ deve deixar o aluno descobrir o mundo em que vivemos, enfocar criticamente a questão ambiental e as relações sociedade/natureza, realizar constantemente estudos do meio, contribuir para a construção da cidadania; deve visar o desenvolvimento da capacidade de apreensão da realidade do ponto de vista da sua espacialidade; deve considerar o aluno como sujeito do processo de ensino-aprendizagem; propiciar 
que o educando compreenda e conheça a realidade em que vive; deve construir os conceitos - conhecimentos cotidianos confrontados com as formulações teóricas; deve variar a escala de análise para compreender a totalidade da problemática espacial dentro de um processo que vai "do particular ao geral e retorna enriquecido ao particular" e deve utilizar diferentes instrumentos e linguagens.

O objetivo da Geografia no ensino fundamental e médio não é formar geógrafos, mas sim contribuir para a construção da cidadania (Pontuschka, 1994). Uma Geografia que se coloca capaz de contribuir efetivamente com a proposta de educar para o exercício da cidadania - em uma educação voltada para a formação cidadã. Dessa forma, devem-se redimensionar os conteúdos escolares como ferramentas que servirão para os alunos produzirem seus próprios conhecimentos, desde que haja sentido e se relacionem com a prática cotidiana e com os demais conhecimentos anteriormente construídos por esses sujeitos sociais (Moura \& Alves, 2002).

A missão da Geografia no ensino é a de alfabetizar o aluno na leitura do espaço geográfico, em suas diversas escalas e configurações (Pereira, 1995). Para cumprir tal objetivo é preciso que se selecione e se organize os conteúdos que sejam significativos e socialmente relevantes. A leitura do mundo do ponto de vista de sua espacialidade, demanda a apropriação pelos alunos de um conjunto de instrumentos conceituais de interpretação e questionamento da realidade socioespacial (Cavalcanti, 1998).

A esse respeito Catellar e Vilhena (2010) apontam que o essencial é dar a todos não o ensino geográfico, mas uma educação geográfica cujo fim é conseguir que os homens não se sintam mal nos seus espaços e meios, dentro de suas próprias paisagens e regiões, mas também nas paisagens e regiões de civilizações que não são as suas. A educação geográfica contribui para que os alunos reconheçam a ação social e cultural de diferentes lugares, as interações entre as sociedades e a dinâmica da natureza que ocorrem em diferentes momentos históricos.

O aluno deve conhecer a organização do espaço geográfico não apenas como um lugar em que se encontram os objetos técnicos, transformados ou não, mas em que há também relações simbólicas e afetivas que revelam as tradições e os costumes indo para além das relações entre o ser humano e a natureza e, consequentemente, avaliando as intervenções humanas no meio físico (Castellar \& Vilhena, 2010).

\section{O Papel da Geografia Física}

A Geografia Física estuda os processos e as características de formação da Terra, incluindo as atividades humanas que causam interferência no meio ambiente. Os geógrafos, em geral, usam uma abordagem holística, ou seja, eles consideram tanto fenômenos naturais quanto humanos que sejam relevantes para a compreensão do nosso planeta (Petersen, Sack \& Gabler, 2014).

A Geografia física, enquanto ramo específico de estudo da ciência geográfica, surgiu com o aparecimento da Geografia regional de Vidal de La Blache na França do século xıx. A viagem de descobrimentos e reconhecimentos científicos desenvolvidas pelos europeus acabou por produzir uma Geografia excepcionalmente descritiva e narrativa dos lugares (Mendonça, 2001). $O$ autor destaca que esse saber geográfico não deve ser qualificado de menos geográfico pelo fato unicamente de tratar a natureza e não considerar as relações da sociedade com o meio natural, pois boa parte dos trabalhos era desenvolvida em regiões praticamente virgens, não sendo possível levar em consideração a análise de uma sociedade inexistente.

Na Geografia regional de La Blache, a Geografia Física não era tratada dentro de um enfoque analítico, era uma mera descrição do quadro natural que poderia influenciar as atividades humanas, um simples apêndice da Geografia humana. Em função da falta quase total de um método analítico, essa Geografia regional possibilista incorreu em estagnação e involução, principalmente referente à abordagem do quadro natural das regiões. Essa Geografia estava fadada a acabar se não fosse o desenvolvimento de suas subdivisões, ocorrido logo a seguir do declínio (Mendonça, 2001).

O fraco enfoque dado aos aspectos naturais individualmente nas abordagens naturalistas levou ao estudo separado dos vários componentes do meio. Assim deu-se o aparecimento individualizado da climatologia, da geomorfologia, da biogeografia, da hidrografia, passando a se constituir os ramos de estudo e pesquisas em Geografia física, em subdivisões do conhecimento geográfico (Mendonça, 2001).

Nos anos 50, a Geografia física caracterizou-se então pelos estudos do quadro natural do planeta, tratados de maneira individualizada entre si e completamente distantes da Geografia humana, constituindo-se verdadeiramente em uma ciência da natureza apartado do princípio básico da Geografia geral (Mendonça, 2001).

A organização do espaço mundial após a segunda guerra mundial provocou alterações tão marcantes no quadro físico do planeta e estabeleceu zonas de influência de potências e o espaço foi organizado entre países socialistas e capitalistas. Nos primeiros, ficou enfraquecido o desenvolvimento das ciências humanas em função da censura à crítica do sistema. Nos países capitalistas os questionamentos sociais e da organização do poder auxiliaram no desmascaramento de injustiças sociais, bem como permitiram avançar no progresso da democracia. A Geografia humana foi quem mais lucrou com a influência ideológica dentro das ciências (Mendonça, 2001).

A separação entre Geografia humana e física não diminuiu, pois, a primeira se aproximava mais da sociologia e a segunda, mais das ciências da terra e da natureza (Mendonça, 2001). Até meados do século xx o enfoque físico-geográfico esteve mais voltado ao desvendamento da natureza, evidenciando suas diferentes manifestações espaço-temporais, caracterizando uma fase caracteristicamente exploratória e descritiva. Nessa perspectiva, a paisagem geográfica era tomada sob uma concepção fragmentada e com elementos desconexos, importando, sobretudo, o conhecimento aprofundado de seus constituintes: litosfera, hidrosfera, atmosfera e biosfera (Mendonça, 2009). 
O emprego da Teoria dos sistemas, modelização e quantificação marcaram profundamente a produção da Geografia física durante as décadas de 50 e 60, valorizando a análise de fenômenos específicos e suas inter-relações. O surgimento do método geossistema marcou este período (Mendonça, 2001).

A emergência da questão ambiental nos anos 60 ressaltou o importante papel desempenhado pela natureza na manutenção da vida e denunciou as políticas que favoreciam a exploração dos recursos naturais e a poluição do meio ambiente. Essa situação influenciou os trabalhos da Geografia Física durante a década de 70, configurando como uma aproximação com a Geografia humana (Mendonça, 2001). O autor coloca que essa nova linha de pensamento em Geografia física tem como pressuposto o fato de que a natureza, de acordo com suas leis próprias, deve ser encarada através de seu próprio sistema de organização e separada da sociedade. A diferença para a abordagem contemporânea é a sociedade, enquanto produtora de ações transformadoras do quadro natural, influenciando-o e sendo influenciada por ele, é incorporada aos estudos de Geografia física. A relação de troca de forças e energia entre a sociedade e a natureza colocou a ação antrópica como elemento componente do quadro natural.

A degradação ambiental tem sido a tônica da Geografia física contemporânea. A necessidade de compreender a organização social e sua interferência nos processos naturais provocando sua degradação tem sido um aspecto cobrado aos geógrafos físicos, levando-os a estudar os processos de organização e transformação social que se relacionam com seu objeto de estudo, fato que tem permitido bastante aproximação com a Geografia Humana (Mendonça, 2001).

A ação humana ganha, de maneira lenta, cada vez mais forte importância na análise físico-geográfica, constituindo-se em um fator dinamizador da paisagem e não um de seus elementos componentes na perspectiva da Geografia física (Mendonça, 2009). A questão e problemática ambiental demandam um considerável esforço dos geógrafos, particularmente aos geógrafos físicos, quais sejam, o de envolver a sociedade humana de maneira mais direta no tratamento dos impactos e riscos que envolvem a degradação ambiental generalizada que se expressa nas paisagens da Terra (Mendonça, 2009).

A emergência da questão ambiental vai definir novos rumos à Geografia Física, fazendo com que as preocupações dos geógrafos atuais se vinculem à demanda ambiental. Por conseguinte, não abandonam a compreensão da dinâmica da natureza, mas cada vez mais não desconhecem e incorporam em suas análises a avaliação das derivações da natureza pela dinâmica social (Suertegaray \& Nunes, 2001). A Geografia, ao incluir no rol de suas pesquisas a questão ambiental, não pode omitir-se da discussão sobre o poder político e sobre a participação coletiva (a prática da cidadania) na sociedade (Suertegaray \& Schàffer, 1988).
Com efeito, a Geografia no Brasil deve tratar a questão ambiental no contexto do capitalismo, onde as acentuadas desigualdades sociais se expressam também e fortemente, na relação do homem com seu ambiente, quando entram em conflito os mecanismos que regem a reprodução do capital com os interesses coletivos por um ambiente de razoável qualidade (Suertegaray \& Schàffer, 1988).

Atualmente os geógrafos físicos contribuem com uma visão holística e espacial, olhando para os fatores, características e processos que influenciam o meio ambiente e como esses elementos interagem (Petersen, Sack \& Gabler, 2014). Se a formação do aluno estiver orientada para a transformação da sociedade, numa direção de maior justiça e bem-estar social, a abordagem ambiental oferece excelente alternativa de reflexão crítica (Suertegaray \& Schàffer, 1988).

Os conteúdos geográficos ministrados na Educação Básica devem ser apoiados na abordagem geossistêmica como uma metodologia unificadora dos estudos geográficos. Prioriza-se compreender a relação sociedade-natureza em uma perspectiva de integração, acentuando não somente os aspectos naturais em detrimento dos sociais ou vice-versa. Evitando-se, assim, incorrer em erros dicotômicos. Destarte, as relações dinâmicas entre os processos sociais e naturais devem ser pautadas em uma perspectiva dinâmica, que envolva relações dialéticas entre natureza, sociedade e estruturas sócio espaciais temporalmente determinadas. Tornando evidente a importância do entendimento da dinâmica da paisagem, na qual há intrínseca relação entre aspectos físicos e humanos (Lopes, 2009).

Compreender a Geografia física nos ajuda a avaliar as condições ambientais, analisar os fatores envolvidos e fazer escolhas conscientes entre possíveis cursos de ação (Petersen, Sack \& Gabler, 2014). Os autores colocam que os processos naturais envolvidos são diretamente relacionados ao ambiente físico, mas as causas e as soluções subjazem nas interações humano-ambientais que incluem características econômicas, políticas e sociais das culturas envolvidas.

O reconhecimento da Geografia como uma disciplina holística, que abrange o estudo de todos os fenômenos na Terra, requer que os geógrafos físicos tenham mais participação nas ciências ambientais. Sabendo que o ambiente físico afeta o nosso cotidiano, é evidente, então, que o estudo da Geografia física e o conhecimento do ambiente natural que ela proporciona são valiosos para todos nós (Petersen, Sack \& Gabler, 2014).

Contudo, Costa e Costa (2003) afirmam que os temas específicos próprios dos ramos da Geografia Física estão sendo, aos poucos, substituídos e negligenciados graças à baixa expressividade que possuem nos vestibulares. Os autores identificaram uma diminuição do número de questões que envolvem apenas conhecimentos de Geografia Física, relacionando-a, assim, a outros temas nas provas de vestibulares. Antes, as 
questões ligadas a essa temática eram simplistas e, mais uma vez, exigindo ampla memorização de nomes de solos, tipos climáticos e nomes de rios, entre outros, agora fazem com que os alunos busquem entender os processos, suas causas e consequências. Sendo percebida uma interação - e até mesmo uma substituição - da conhecida Geografia Física com as temáticas ligadas ao Meio Ambiente.

Em uma rápida análise das provas de Geografia do ENADE (Exame Nacional do Desempenho dos Estudantes) dos anos de 2005, 2008, 2011 e 2014 é possível perceber uma prevalência das questões ligadas à área humana da Geografia. Contudo, as questões referentes aos conteúdos físicos apresentam-se ligadas à questão ambiental, enfatizando os processos naturais e a problemática ambiental entorno do tema.

\section{Referências}

Brabant, J. (2003). Crise da Geografia, Crise da Escola. In Oliveira, A. de. (Org.), Para onde vai o ensino de Geografia? Crise da Geografia, da escola e da sociedade. São Paulo, Brasil: Contexto.

Castellar, S., \& Vilhena, J. (2010). Ensino de Geografia. São Paulo, Brasil: Cengage.

Cavalcanti, L. de. (1998). Geografia, escola e construção de conhecimentos. Campinas, Brasil: Papirus.

Costa, K., \& Costa, A. (Novembro de 2003). As Mudanças na Abordagem e a Diminuição da Presença da Geografia Física no Ensino Médio: Um Estudo das Provas de Vestibulares (1974/2003) no Rio De Janeiro. In X Simpósio Brasileiro de Geografia Física Aplicada. Rio de Janeiro, Brasil.

Kozel, S. (1998). Ensinar Geografia no terceiro milênio. Como? Por quê? RA'E GA-O Espaço Geográfico em Análise, 2, 141-151.

Lopes, L. (2009). A Geografia Física numa Perspectiva Sistêmica Aplicada ao Ensino. Enciclopédia Biosfera, 5(8).

Mendonça, F. (2001). Geografia Física: Ciência Humana? (7. ed.). São Paulo, Brasil: Contexto.

Mendonça, F. (2009). Geografia, Geografia Física e Meio Ambiente: Uma Reflexão À Partir Da Problemática Socioambiental Urbana. Revista da ANPEGE, (5), 123-134.

\section{Considerações finais}

A ciência geográfica volta-se para o estudo da organização espacial e seu ensino deve propiciar ao aluno uma correta leitura do espaço geográfico em suas diferentes dimensões ambiental, política, econômica, social e cultural, tendo por objetivo contribuir para a construção da cidadania. Já a Geografia Física volta-se para o conhecimento aprofundado da composição e dinâmica processual da natureza, bem como as derivações oriundas de sua apropriação e transformação pela sociedade, sendo a degradação ambiental a tônica deste ramo da ciência. Portanto, deverá permitir uma visão holística da realidade, olhando para os fatores, características e processos que influenciam o meio ambiente e como esses elementos interagem, assegurado uma correta análise do espaço, mantendo o princípio de uma Geografia global.

Moura, J., \& Alves, J. (2002). Pressupostos teórico-metodológicos sobre o ensino de geografia: Elementos para a prática educativa. Geografia (Londrina), 11(2), 309-320.

Oliveira, A. (2003). Situação e tendência da Geografia. In Oliveira, A. (Org.), Para onde vai o ensino de Geografia? (8. ed.). São Paulo, Brasil: Contexto.

Pereira, D. (1995). Geografia Escolar: conteúdos e/ou objetivos? Caderno Prudentino de Geografia, (17).

Pereira, R. (2009). Da Geografia que se ensina à gênese da Geografia moderna. (3. ed.). Florianópolis, Brasil: UFSC.

Petersen, J., Sack, D., \& Gabler, R. (2014). Fundamentos de Geografia Física. São Paulo, Brasil: Cengage Learning.

Pontuschka, N. (1994). A formação pedagógica do professor de Geografia e as práticas interdisciplinares (tese de doutoramento). Universidade de São Paulo, São Paulo, Brasil.

Suertegaray, D., \& Schàffer, N. (1988). Análise Ambiental: a Atuação do Geógrafo Para e Na Sociedade. Porto Alegre: a metrópole e seu delta. Terra Livre, (3), 89-104.

Suertegaray, D., \& Nunes, J. (2001). A natureza da Geografia física na Geografia. Terra Livre, (17), 11-24.

Vesentini, J. (2003). Geografia Crítica e Ensino. In Oliveira, A. (Org.), Para onde vai o ensino de Geografia? São Paulo, Brasil: Contexto. 